\title{
On the morphodynamic stability of intertidal environments and the role of vegetation
}

\author{
Nabil Kakeh ${ }^{\mathrm{a}}$, Giovanni Coco $^{\mathrm{b}}$, Marco Marani ${ }^{\mathrm{c}, \mathrm{d}}$ \\ ${ }^{a}$ Department of Applied Physics, Universitat Politecnica de Catalunya, Barcelona, Spain \\ ${ }^{b}$ School of Environment, University of Auckland, Auckland, New Zealand \\ ${ }^{c}$ Earth and Ocean Sciences Division and Civil and Environmental Engineering \\ Department Duke University, USA \\ ${ }^{d}$ Department of Civil, Environmental and Architectural Engineering University of \\ Padova, Italy
}

\begin{abstract}
We describe the coupled biotic and abiotic dynamics in intertidal environments using a point model that includes suspended sediment deposition, wave- and current-driven erosion, biofilm sediment stabilization, and sediment production and stabilization by vegetation. We explore the effects of two widely different types of vegetation: salt-marsh vegetation and mangroves. These two types of vegetation, which colonize distinct geographical areas, are characterized by different biomass productivities and stabilization mechanisms. Our results show the number and types of system stable states determined as vegetation and biofilm properties are varied. The presence of the biofilm exerts a dominant control on the tidal flat (lower intertidal) equilibrium elevation and stabilitiy. Vegetation controls the upper intertidal equilibrium. and the two types of vegetations considered, even though they are characterized by distinct biophysical interactions, they ultimately lead to similar effects on the stability of the system.
\end{abstract}

Keywords: ecogeomorphology, biomorphodynamics, biofilm, sediment transport, intertidal flat, salt marsh

\section{Introduction}

Ecogeomorphology, or biomorphodynamics, is a novel discipline that studies how the feedbacks between biotic and abiotic processes shape Earth's surface. The importance of biological effects on sedimentary processes was 
first discussed by Darwin, who, in 1881, studied the role of bioturbation on sedimentary dynamics (Darwin, 1881/2013). Darwin predicted that the study of sediment transport in natural environments would have to incorporate the effects of biological processes. Earth science totally disregarded Darwin's suggestion and only after more than 100 years are we now beginning to understand that biology plays a key role in morphodynamics through feedbacks that affect water and sediment transport processes. The presence of such feedbacks implies that not only biological processes affect geomorphological evolution, but also that organisms are in turn affected by the evolving geomorphology (Murray et al., 2008). The importance of eco-geomorphology is aptly embodied by the case of tidal landscapes, such as estuaries and coastal embayments, where it has been extensively studied (e.g., Morris et al. (2002); Marani et al. (2007); Kirwan and Murray (2007); D'Alpaos et al. (2007b); Mariotti and Fagherazzi (2010); Temmerman et al. (2007); Marani et al. (2013)). Tidal landscapes are dissected by a network of tidal channels (D'Alpaos et al., 2007b; Coco et al., 2013) separating relatively flat areas (tidal platforms) positioned at different, but characteristic, elevations: subtidal areas (permanently submerged), tidal flats (usually non-vegetated zones approximately located between low tidal level and mean sea level), and vegetated upper intertidal areas (marshes and mangroves, located between mean sea level and high tidal level). Here we focus on the accretionary dynamics and transformations of these characteristic landforms, regulated as they are by two-way interactions among physical and biological processes (Marani et al., 2010). Vegetation plays a key role in the upper intertidal zone, where it produces organic soil, traps suspended sediment, and stabilizes the soil surface, thus exerting a strong control on the elevation of salt-marsh areas (e.g., D'Alpaos et al. (2007a); Mudd et al. (2009, 2010); Marani et al. (2013); Da Lio et al. (2013)). Marsh vegetation also fundamentally affects flow resistance (Nepf, 2012), and thus interacts with channel formation processes (Temmerman et al., 2012; Vandenbruwaene et al., 2012) and the topography-hydrodynamics feedback widely regarded as the chief network formation mechanism (D'Alpaos et al., 2007b).

Concerns about marshes ability to maintain their elevation relative to an increasing sea level rise have spurred a considerable amount of research focusing on the mechanisms regulating marsh accretion (Morris et al., 2002; Marani et al., 2007; Kirwan and Murray, 2007). These works explored the existence, and nature, of equilibrium configurations under different scenarios of rate of relative sea-level rise, inorganic sediment availability, and tidal 
amplitude.

Here we build on the approach described in Marani et al. (2007) and Marani et al. (2010), who couple equations describing vegetation and "vertical"' elevation dynamics in a 0D framework, finding that alternative stable states exist and that changes in the rate of sea level rise and in other forcings (e.g. sediment availability) can induce transitions from one state to another.

These previous studies have highlighted the importance of vegetation in affecting the feedback processes driving morphological evolution, yet only a limited range of vegetation species have been examined. The focus has been usually directed towards species present at higher latitudes (e.g. along the Atlantic and Mediterranean coasts). Yet, a large part of the world's tidal environments, in tropical and subtropical areas, are dominated by mangroves (Spalding et al., 2010). Mangrove trees are characterized by bio-stabilization effects similar to those occurring in marshes, but their geomorphic implications have only just began to be explored. At present most studies deal with the interactions between mangroves, hydrodynamics and sediment transport (e.g. Furukawa et al. (1997)), by means of small-scale field experiments and only recently a large-scale nonlinear morphodynamic model has been developed to study the evolution of the whole biophysical system (van Maanen et al., 2011, 2015).

Here we develop a general model that couples physical and biological processes typical of tidal environments and we explore the role of different vegetation types in determining possible stable states and the transitions among them. We also explore the importance of benthic biofilms generated by microphytobenthos (a collection of microalgae and microbial assemblages colonizing intertidal soils, e.g. Malarkey et al. (2015)), a known but poorly understood bio-geomoprhic factor, which regulates erosion and sediment transport in tidal flats and in the upper intertidal zone. Following Marani et al. (2010), we use a stability analysis approach to look at the evolution of the coupled sediment-vegetation-system. While using their same description for the physical system, we adopted different modelling frameworks to describe different vegetation types, from grassy alophytic vegetation, e.g. Spartina, to woody mangroves. We subsequently analysed the dynamical implications of the different biological processes associated with such vegetations species. 


\section{Methodology}

We use the 0-D modelling approach proposed by Marani et al. (2010) to describe the average mean tidal platform elevation $z(t)$ (with respect to mean sea level - MSL) and the vegetation density of biomass $B(t)$. Additionally, we consider the time evolution of the biofilm biomass $\chi(t)$. As our interest lies in studying the long-term stability of the system we have assumed that intra-annual variations of vegetation and platform elevation are negligible.

\subsection{Physical model}

Figure 1 shows a sketch of the physical system considered. The platform is subject to a sinusoidal tide, of period $\mathrm{T}$ (we used here $\mathrm{T}=12 \mathrm{hrs}$, the fundamental periodicity of tidal oscillations) and amplitude $\mathrm{H}$. The suspended sediment concentration flux from the water column is deposited on the platform as a result of settling and trapping processes. Moreover, root growth produces organic soil (after oxidation of the labile organic material) and cause soil expansion which contributes to platform accretion. Finally, waves may cause platform erosion and produce sediment transport.

According to (Marani et al., 2010), we can express the long-term evolution of the platform as:

$$
\frac{d z}{d t}=Q_{S}(z, B)+Q_{T}(z, B)+Q_{O}(B)-E[z, B]-R
$$

$Q_{S}$ is the settling flux, which is proportional to the settling velocity $w_{s}$ :

$$
\frac{d z_{s}}{d t}=\frac{w_{s}}{\rho_{b}} C(z, B, t)
$$

where $d z_{s} / d t$ is the elevation change due to the settling flux, $\rho_{b}$ is the sediment bulk density, $\rho_{b}=\rho_{s}(1-\lambda)\left(\rho_{s}=2650 \mathrm{~kg} / \mathrm{m}^{3}\right.$ for an inorganic material), and $\lambda=0.5$ is the porosity (i.e. the final porosity once the sediment is deposited and compacted). The instantaneous sediment concentration on the tidal platform $C(z, B, t)$ (mass of sediment per unit volume of the water column) depends on the vegetation density (through trapping) and the instantaneous water depth. The tidal elevation with respect to the local mean sea level (MSL) is $h(t)$ and the instantaneous water depth is equal to $D(t)=h(t)-z$.

As noted in (Marani et al., 2010), the time scale of change of $h(t)$ (order of tens of minutes), is much more rapid than the time scale of change of 
$z(t)$ (order of years to tens of years). Hence the settling deposition over a tidal cycle can be averaged by assuming $z(t)$ to be constant. Consequently, the mean settling flux to the platform surface can be expressed as:

$$
Q_{S}(z, B)=\frac{w_{s}}{\rho_{b}} \frac{1}{T} \int_{T} C(z, B, t) d t
$$

Trapping is the process by which particles suspended in the water column are intercepted by vegetation and are eventually deposited on the soil surface. The sediment flux to the soil surface associated with trapping can be expressed as:

$$
Q_{T}(z, B)=\frac{\alpha_{T} B^{\beta}}{\rho_{b}} \frac{1}{T} \int_{T} C(z, B, t) d t
$$

where $\beta=0.382$ and $\alpha_{T}=1.02 \cdot 10^{6} d_{50}^{2} U^{1.7} \mathrm{~m} / \mathrm{s}\left(\mathrm{m}^{2} / \mathrm{g}\right)^{\beta}$ (this formulation and the associated parameterizations are taken from Marani et al. (2010)). The average tidal flow velocity and grain size are here assumed to be $U=0.02 \mathrm{~m} / \mathrm{s}$ (a typical order of magnitude) and $d_{50}=50 \mu \mathrm{m}$, respectively.

In order to solve eqs. (3) and (4) we must determine the sediment concentration, $C(z, B, t)$, over the tidal platform. If we assume that the concentration is constant over the water column, the total mass of suspended sediment per unit area is equal to $D(t) \cdot C(t)$. We can now express the rate of change in the mass of sediment in the water column as the sediment exchanged between the tidal platform and the surrounding environment minus the sediment deposited on the marsh surface due to settling and trapping (Temmerman et al., 2003; Marani et al., 2007):

$$
\frac{d C_{s}}{d t}=\frac{d(D \cdot C)}{d t}=\hat{C} \frac{d h}{d t}-\left(w_{s}+\alpha_{T} B^{\beta}\right) C
$$

The first term represents the sediment flux exchanged between the platform and the lagoon. When the tide is rising, the flux is positive, from the lagoon to the platform. When the tide is falling, the the flux is negative, from the platform to the lagoon. If $C_{0}$ is the average suspended sediment concentration in the lagoon, we can express the term $\hat{C}$ as (French, 1993; Mudd et al., 2004; Marani et al., 2010):

$$
\hat{C}(z, t)=\left\{\begin{array}{cc}
C_{0} & \text { when } \frac{d h}{d t}>0 \\
C(z, t) & \text { when } \frac{d h}{d t}<0
\end{array}\right.
$$


The term $Q_{O}(B)$ in Equation 1 represents the elevation change due to soil expansion driven by organic matter production, accumulation and decomposition. According to various authors (Mudd et al. (2004), D'Alpaos et al. (2006), D'Alpaos et al. (2007a)) such term can be considered to be proportional to the biomass, $B$ :

$$
Q_{O}(B)=\frac{d z_{O}}{d t}=\gamma B
$$

where $\gamma$ is a parameter that depends on soil and vegetation characteristics and on the decomposition rate (largely controlled by soil aeration), and may take a value in the range $1-3(\mathrm{~mm} / \mathrm{yr})\left(\mathrm{m}^{2} / \mathrm{g}\right.$ ) (a value of 2 is used unless otherwise indicated).

Erosion is produced by the sediment being resuspended from the platform surface. The erosion rate is usually expressed as a function of the normalized shear stress exceedance $\bar{\tau}$ (Carniello et al., 2005; Fagherazzi et al., 2006; Defina et al., 2007):

$$
\bar{\tau}\left[D(t), U_{w}, B, \chi\right]=\frac{\tau\left[D(t), U_{w}\right]-\tau_{c}[B, \chi]}{\tau_{c}[B, \chi]}
$$

where $\tau$ and $\tau_{c}$ are the shear stress and the critical shear stress. We consider here that $\tau$ is locally generated by wind waves (contributions by tidal flows being significant only in macrotidal environments). It is calculated from wind wave height and wave period, $H_{w}$ and $T_{w}$ as (see Green and Coco (2014) for a review):

$$
\begin{array}{r}
\tau=\frac{1}{2} \rho_{w} c_{f} U_{r m s}^{2} \\
c_{f}=\exp \left(5.213\left(\frac{2.5 d_{50}}{A_{w}}\right)^{0.194}-5.977\right) \\
A_{w}=\frac{T_{w} U_{r m s}}{2 \pi} \\
U_{r m s}=\frac{\pi H_{w}}{T_{w} \sinh k D}
\end{array}
$$

where $\rho_{w}$ is the water density. In this work we use an empirical formulation $(\mathrm{CERC}, 1984)$ to estimate $H_{w}$ and $T_{w}$ from the wind velocity, $U_{w}$ :

$$
H_{w}=\frac{U_{a}^{2} \alpha_{1 w}}{g} \tanh \left(\beta_{1 w} k_{d}^{3 / 4}\right) \tanh \left(\frac{\gamma_{1 w} \sqrt{k_{f}}}{\tanh \left(\beta_{1 w} k_{d}^{3 / 4}\right)}\right)
$$




$$
\begin{gathered}
T_{w}=\frac{U_{a} \alpha_{2 w}}{g} \tanh \left(\beta_{2 w} k_{d}^{0.375}\right) \tanh \left(\frac{\gamma_{2 w} k_{f}^{1 / 3}}{\tanh \left(\beta_{2 w} k_{d}^{0.375}\right)}\right) \\
U_{a}=0.71 U_{w}^{1.23} \\
k_{d}=\frac{g D}{U_{a}^{2}} \\
k_{f}=\frac{g L}{U_{a}^{2}}
\end{gathered}
$$

where $L$ is the fetch length and $\alpha_{1 w}=0.283 ; \beta_{1 w}=0.530 ; \gamma_{1 w}=0.00565$; $\alpha_{2 w}=0.7 .54 ; \beta_{2 w}=0.833 ; \gamma_{2 w}=0.0379$

The critial shear stress, $\tau_{c}$, depends on several factors such as vegetation presence and the amount of biofilm layer. Following (Mariotti and Fagherazzi, 2012):

$$
\tau_{c}=\tau_{c 0}\left(1+K_{c r} \frac{B}{B_{\max }}\right)+\alpha \chi
$$

where $\tau_{c 0}$ is the critical shear stress of the bare sediment. This parameter takes on values between $0.1-0.4 P a$; $\chi$ is the biomass density of the biofilm layer; $\alpha$ takes on values between $0.001-0.02 \mathrm{~Pa} /\left(\mathrm{mg} / \mathrm{m}^{2}\right)$, (Mariotti and Fagherazzi, 2012); $K_{c r}$ describes the sediment stabilization associated with the presence of roots, as well as the reduction of the shear stress due to the vegetation canopy.

In order to compute 15, we use a biofilm evolution model based on the work of Mariotti and Fagherazzi (2012). The growth of biofilm biomass $\chi$ is described according to:

$$
\frac{d \chi}{d t}=\mu_{e} \frac{\chi}{1+K_{s} \chi}-\epsilon\left(\chi-\chi_{b}\right)-E_{x}
$$

where $\mu_{e}=\hat{\mu}_{e} \sin (\pi P)$ is the effective maximum grown rate which takes into account light attenuation and the effect of the hydroperiod $P$ (here defined as the fraction of the tidal period during which the tidal level is higher than the local elevation), $\hat{\mu}_{e}=1$ day $^{-1} ; K_{s}=0.02 \mathrm{~m}^{2} / \mathrm{mg}$ is the half-saturation constant; $\epsilon=0.2$ day $^{-1}$ is a global decay parameter; $\chi_{b}=1 \mathrm{mg} / \mathrm{m}^{2}$ is the biofilm background value; the term $E_{x}$ takes into account the instantaneous detachment due to catastrophic events.

$$
E_{x}=\left\{\begin{array}{c}
0 ; \quad \tau \leq \tau_{c} \\
\epsilon_{x}\left(\chi-\chi_{b}\right) ; \tau \geq \tau_{c}
\end{array}\right.
$$


where $\epsilon_{x}=1$ day $^{-1}$. The hydroperiod associated with elevation $\mathrm{z}$ when tidal fluctuations are sinusoidal can be calculated using:

$$
P=\frac{1}{2}-\frac{\arcsin (z / H)}{\pi}
$$

The biofilm time scale of evolution is of the order of days (Mariotti and Fagherazzi, 2012), and we are interested in simulating long-term morphodynamic changes over tens of years or centuries. In order to decrease the computational cost, we use a quasi-steady approach of the biofilm modelling:

$$
\chi_{s}\left(U_{w}, t_{w}\right)=\chi_{0}-\int_{0}^{t_{w}} E_{x}\left(U_{w}\right) d t
$$

$\chi_{0}$ is the saturated, steady-state amount of biofilm in absence of critical events. From Eq. (16), with $\frac{d \chi}{d t}=0$ and $E x=0$ :

$$
\chi_{0}^{2} \cdot K_{s} \epsilon+\chi_{0} \cdot\left(\epsilon-\mu_{e} K s \chi_{b}\right)-\epsilon \chi_{b}=0
$$

The second term of (19), describes the biofilm detachment due to extreme wave conditions and depends on the wind velocity, $U_{w}$, and duration of the extreme event, $t_{w}$. Therefore, given a wind velocity the normalized exceedence of shear stress can be expressed as:

$$
\bar{\tau}\left[D(t), U_{w}, B\right]=\int_{t_{w}} \frac{\tau\left[D(t), U_{w}\right]-\tau_{c}\left[B, \chi_{s}\left(U_{w}, t_{w}\right)\right]}{\tau_{c}\left[B, \chi_{s}\left(U_{w}, t_{w}\right)\right]} f_{U_{w}}\left(t_{w}\right) d t_{w}
$$

where $f_{U_{w}}\left(t_{w}\right)$ is the probability distribution of time periods with wind speed higher than $U_{w}$.

Equation (21) can also be averaged over a tidal cycle (as done earlier with the settling and trapping terms):

$$
E_{w}\left[z, B, U_{w}\right]=\frac{e}{\rho_{b}} \frac{1}{T} \int_{T} \bar{\tau}\left[D(t), U_{w}, B\right] d t
$$

where $e$ is the erosion coefficient, $e=10^{-4} \mathrm{~kg} \mathrm{~m}^{-2} \mathrm{~s}^{-2}$

The erosion is then averaged over the probability distribution of wind velocity (Marani et al., 2010):

$$
E[z, B]=\int_{U_{w}} E_{w}\left[z, B, U_{w}\right] f\left(U_{w}\right) d U_{w}
$$

Finally, the Relative Rate of Sea Level Rise (RRSLR), $R$ in eq. (1), is equal to the sum of RRSLR and the local subsidence rate. Unless otherwise stated, we have assumed a constant RRSLR, $R=3.5 \mathrm{~mm} /$ year. 


\subsection{Salt marsh vegetation model}

Salt marsh vegetation is found over a large geographical gradient that covers Arctic to temperate regions (Adam, 1993). In order to describe marsh vegetation dynamics, we follow the methodology originally presented by Marani et al. (2007) (see also Marani et al. (2010) for more details), who express vegetation biomass using a logistic equation:

$$
\frac{d B}{d t}=r B\left(1-\frac{B}{B_{\max }}\right)-m B
$$

where $r, m$ are the reproduction and mortality rates respectively, and $B_{\max }(=$ $1000 \mathrm{~g} / \mathrm{m}^{2}$ here) is the maximum biomass per unit area that can be supported by the marsh. From Eq. (24) we can obtain an analytical solution for nontrivial (i.e. $B \neq 0$ ) steady state conditions, by setting $\frac{d B_{s}}{d t}=0$ (Marani et al., 2007, 2010).

$$
B_{s}=B_{\max }\left(1-\frac{m}{r}\right)
$$

In the stability analyses below, we use Eq. (25), under the assumption assuming that the time scale of the biomass adaptation to a changing elevation is significantly shorter than the time scale of topographic changes (Marani et al., 2010). Eq. (24) is used when simulating the transient temporal evolution of the system.

We assume here that the optimal conditions for vegetation growth occur when the tidal platform is submerged for half of the tidal cycle. So, we express $r$ and $m$ as functions of the hydroperiod, $P$, through simple sinusoidal functions:

$$
\begin{aligned}
r & =\frac{1}{2}(1+\sin (\pi P)) \\
m & =\frac{1}{2}(1-\sin (\pi P))
\end{aligned}
$$

which maximise growth and minimise mortality at an elevation equal to mean sea level, while minimal growth and maximum mortality occur for elevations equal to maximum and minimum tidal levels. This set of assumptions represents the observed behaviour of Spartina sp., one of the most widely spread marsh vegetation species (Morris et al., 2002). 


\subsection{Mangrove vegetation model}

Mangroves are a typical vegetation of temperate subtropical and tropical environments, whose establishment is primarily constrained by temperature and latitude (Spalding et al., 2010). Here, we adapt and use a model representative of Avicennia marina, a type of mangrove present in New Zealand estuaries. We use an individual growth model as presented in van Maanen et al. (2011, 2015), where the temporal evolution of tree height and stem diameter, $M_{h}$ and $M_{d}$, is described by the following equations (Berger and Hildenbrandt, 2000; Chen and Twilley, 1998):

$$
\begin{gathered}
\frac{d M_{d}}{d t}=\frac{G M_{d}\left(1-M_{d} M_{h}\right) /\left(M_{d}^{\max } M_{h}^{\max }\right)}{274+3 b_{2} M_{d}-4 b_{3} M_{d}{ }^{2}} \cdot I \\
M_{h}=137+b_{2} \cdot M_{d}+b_{3} \cdot M_{d}^{2}
\end{gathered}
$$

where $G(\mathrm{~cm} / \mathrm{s}), b_{2}$ (dimensionless) and $b_{3}\left(\mathrm{~cm}^{-1}\right)$ are species-specific growth parameters which are set to $152.17 \mathrm{~cm} / \mathrm{s}, 42$, and $0.46 \mathrm{~cm}^{-1}$, respectively (Chen and Twilley, 1998). The maximum height and stem diameter are $M_{h}^{\max }=1000 \mathrm{~cm}$ and $M_{d}^{\max }=40 \mathrm{~cm}$. $I$ is the correction factor for inundation and can be modelled by a parabolic function over the relative hydroperiod $P$ (van Maanen et al., 2011, 2015):

$$
\begin{gathered}
I=\left\{\begin{array}{cc}
\hat{I} & \text { when } \hat{I}>0 \\
0 & \text { when } \hat{I} \leq 0
\end{array}\right. \\
\hat{I}=a \cdot P+b \cdot P^{2}+c
\end{gathered}
$$

where $\mathrm{a}, \mathrm{b}$, and $\mathrm{c}$ are constants which have been set to $4,-8$, and 0.5 , respectively.

Analogously to the marsh vegetation case, we obtain a steady-state solution which will be used in the long-term stability analysis:

$$
M_{d}=M_{d}^{\max } \cdot I
$$

Equations (28) and (32) limit the maximum growth of the trees and incorporate the observation that mangroves do not grow well when they are permanently inundated. The total biomass $B_{T}$ can be calculated by multiplying the mass of a mangrove, $M_{w}$, by the number of trees per unit area. We focus here on below-ground biomass production, which provides the main contribution to organic soil accretion. In both marshes and mangroves, above ground 
biomass is assumed to negligibly contribute to accretion because, once dead, it is either transported away by tides, or rapidly decomposed, since oxygen is available at the surface. The below-ground biomass, $B=\rho_{t} \cdot M_{w, b}$, is used to calculate the soil accretion by organic production (Eq. (7)), as well as the critical shear stress (eq. (15)). The above- and below-ground biomass are calculated using the following relations (Comley and McGuinness, 2005):

$$
M_{w, a}=0.308 M_{d}^{2.11}, M_{w, b}=1.28 M_{d}^{1.17}
$$

The crown radius of a single tree can be estimated as $R=10 \sqrt{0.5 \frac{M_{d}}{100}}$ (Berger and Hildenbrandt, 2000). Assuming that all the tress have equal size and that they are spatially distributed as a square tiling, we can derive the number of trees per unit area as:

$$
\rho_{t}=\frac{1}{4 R^{2}}=\frac{1}{2 M_{d}}
$$

The most important differences between mangroves and Spartina are that (1) the submerged portion of the canopy is not significant in mangroves and therefore particle capture is neglected, and (2) mangroves tend to have a greater below-ground productivity and induce a larger soil expansion (see the discussion in Friess et al. (2012)).

\section{Results}

We look at the stability of the system by studying the rate of change of elevation in the neighbourhood of the equilibrium states for both types of vegetation considered. Figure 2 shows the sensitivity of the possible equilibrium states of the system to changes in tidal range, fetch (essentially a proxy for wave height) and in the parametrization of the biofilm effect. In general, as pointed out by Marani et al. (2010), not all states where $d z / d t=0$ are necessarily indicative of a stable equilibrium state, a condition that is obtained only when the second derivative of the elevation with respect to time is negative (see the black dots in Figure 2).

The case of a short fetch without biofilm reveals the dependency of stable states on tidal range. For example, the intermediate tidal range and the smallest fetch give rise to two stable states (subtidal and tidal flat) with no evident vegetation effect (Figure 2.b). A larger tidal range (Figure 2.e) leads to the disappearance of the subtidal and tidal-flat stable state and to the 
appearance of a marsh stable state (see also D'Alpaos et al. (2011)). Looking at the individual sediment transport contributions (Figure 3.a and 3.b) one can notice that, while the settling contribution decreases with decreasing tidal range, erosion becomes larger. Hence, the overall wave effect is increased erosion through increased sediment resuspension and reduced settling.

Large fetch values (Figure 2.d, e, f) imply large waves and increased erosion, which leads to the presence of a stable state at a lower subtidal elevation for small tidal range and the disappearance of the tidal flat state (settling is larger than wave erosion only in the subtidal region) for intermediate tidal ranges. Two stable states coexist only for the largest tidal range: a tidal flat (in the low intertidal zone) and a vegetated marsh (just above mean sea level). The effect of an increase in fetch can also be analyzed in terms of the different sediment transport contributions to the overall accretion rate (Figure 3). Comparing Figure 3.a and 3.c one can notice that the contribution related to erosion, always the largest of the four contributions, is almost twice as large when the fetch is doubled.

When biofilm dynamics is included, the shape of the stability curves and the presence of stable states change significantly, rather independently of the actual value of $\alpha$ (see equation 15 and Figure 2). For the smallest tidal range, irrespective of the fetch value, subtidal and marsh stable states are present. For larger tidal ranges only the marsh stable state is present. The role of the biofilm becomes evident when individual contributions are analyzed (Figure 3.d): Erosion becomes negligible when the biofilm is present, while the other sediment fluxes remain unchanged.

Aside from some details in the shape of the stability curves (particularly evident for the case with no biofilm, see the blue lines in Figure 4) results for the mangrove and salt marsh cases are similar. When the tidal range is large the vegetation stable state is present for both types of vegetation, independently of the fetch value. The sharp discontinuity present for the mangrove cases (particularly evident for $\mathrm{H}=0.5 \mathrm{~m}$ at an elevation of about $-0.20 \mathrm{~m}$ ) derives from the specific function describing the relationship between mangrove biomass and inundation. Mangroves strongly affect the shear stress for erosion (which is constant for salt marshes) and the discontinuous function representing erosion. Furthermore, in the mangrove case with an intermediate tidal range and a small fetch distance, no tidal flat state is possible, and only subtidal and vegetated equilibria exist. In terms of contributions to the overall sediment dynamics (Figure 3) similar behaviours are observed for the two vegetation types, with a strong dominance of biofilm stabilization 
on erosional processes (Figure 3.d) and similar dependencies on tidal range and fetch (compare Figure 3.b and c, respectively). Comparing Figure 3 and 5 one can notice that the erosion term is slightly smaller in the mangrove case. However, when the biofilm is present (3.d and 5.d), it dominates the erosion process in both cases. There is a difference between salt marshes and mangroves in the elevation dependence of organic production which increases with elevation for mangroves while it is slightly larger at lower elevations for salt marshes; finally, the trapping term is only present in the case of Spartina.

The critical shear stress for erosion, $\tau_{c}$ (see equation (15)), can be spatially heterogeneous and difficult to evaluate (Venier et al., 2014). We have thus tested the sensitivity of the system stable states to the choice of this parameter value (Figure 6). The general character of the results is as expected: when $\tau_{c}$ is low, the erosion term becomes dominant and only a subtitdal stable state is encountered. This is particularly evident for the case with larger fetch, when wave-induced erosion causes extremely large erosion rates. On the contrary, when $\tau_{c}$ is large, the subtitdal region accretes and transitions to a marsh equilibrium, even for large fetch values.

The observed dependence of the results on the value of $\tau_{c}$ motivated an additional sensitivity analysis to the value of $K_{c r}$ (Figure 7 ), which, for the case of mangroves, represents the increase in the critical shear stress resulting from the presence of a root system (equation $15, K_{c r}$ is set to 0 for the case of Spartina). In principle, this sensitivity analysis is particularly relevant for the mangrove case, since mangroves can develop a large root system and determining its effect on the critical shear stress is extremely difficult. At the same time, it should be acknowledged that comparing mangroves and marshes is difficult since the spacing of mangrove roots is usually large compared to the spacing of salt marshes (marsh vegetation produces a dense root mat, whereas mangroves have large woody roots separated by areas with lower root mass). Thus, while it is evident that the mangrove substrate might be extremely resilient to large removal events (e.g., storms), the marsh root mat might provide more local protection against erosion. Model experiments for the case with no biofilm show that $K_{c r}$ can change the overall behavior of the system: The vegetated stable case is only found for large values of $K_{c r}$ (the subtidal stable sate is not affected by the analysis, biofilm and $K_{c r}$ have no effect at lower elevations). Also these experiments with $K_{c r}$ support the idea that, once biofilm dynamics are included, they are likely to overwhelm all other physical and biological contributions (Figure 7.b and c).

The sensitivity of the system to the suspended sediment concentration in 
the tidal platform, $C_{0}$, is explored in Figure 8. Changes in $C_{0}$ can potentially cause a shift the system from a two-stable-state configuration (subtidal and vegetated), for small $C_{0}$, to a case characterized by a single vegetated stable state at an elevation just below the high tide limit (for a higher $C_{0}$ value). The right panel in Figure 8 shows the stable and unstable states for $C_{0}$ equal to 10 and $50 \mathrm{~g} / \mathrm{m}^{3}$ for the Spartina and mangrove cases. At negative depths the solutions for the two cases overlap since vegetation has no effect on subtidal dynamics. A vegetated stable state always exists in both cases.

The sensitivity to different values of the RRSLR has also been explored (Figure 9). The subtitdal stable state is essentially unaltered by changes in

the RRSLR. On the other hand, an increase in RRSLR causes a decrease of the vegetated equilibrium vegetation (compare for example the green and the blue lines in Figure 9, left panel, and consider that the initial high tide mark is at an elevation of $1 \mathrm{~m}$ ). Also in this case, results are very similar when a mangrove-type of vegetation is considered (see the right panel of Figure 9).

Figure 10 and Figure 11 show the time evolution of the system starting from different initial conditions. The results provide evidence of the different adaptation times of the two types of vegetation considered (notice the different horizontal scales in Figure 10 and 11). The temporal evolution is calculated for different initial elevations and the system converges to the subtidal or vegetated stable states depending on the initial elevation. The adaptation time is almost twice is larger for the case of mangrove vegetation but the overall behaviour is consistent between the two cases. If the initial elevation is lower than the subtidal limit, the system will rapidly accrete since settling largely exceeds erosion. Reaching the vegetated stable state requires much longer times because of the subtle balance between erosion (which is a nonlinear function of elevation), trapping, and settling.

\section{Discussion and Conclusions}

The simplified point-modelling approach adopted here provides insight into how bio-geomorphic feedbacks can affect the sediment balance and hence the stability of estuarine environments characterized by different vegetation types. The model shows that multiple stable equilibria are possible. Stable points correspond to subtidal, tidal flat and vegetated regions of the domain. These regions are marked by different elevations and thus by a different balance between terms affecting the sediment budget. For example, erosion plays a minor role in the subtidal region, while it dominates in the intertidal 
range and again is reduced in the vegetated zone (Figure 12). Figure 12 provides an overall summary of the results obtained and evidence of the interplay between the different processes in the model.

When no erosion is present (a result obtained for large values of the the biofilm growth, Figure 12.a) soil accretion due to organic growth plays a dominant role in the intertidal region, particularly for elevations $-H<z<$ $+H$ (with $H=1 \mathrm{~m}$ for this specific run), while the effect is limited at low and high elevations, where vegetation biomass is small or absent. In this case only a tidal flat stable state is possible. Once biofilm growth is set to a more realistic value (Figure 12.b), the dynamics of the low intertidal area change and a subtitdal stable state is present, but biofilm effects still dominate over erosion in most of the intertidal zone. Hence, results are essentially unchanged as compared to the no-erosion case. Once the biofilm is entirely removed (Figure 12.c), erosion becomes the dominant process in the intertidal zone leading to the presence of a stable state just below mean sea level, and to the disappearance of the stable state in the upper intertidal zone.

Under simplified assumptions, the model also allows to study how the different terms in the sediment budget balance out for increasing rates of sea level rise. For example, assuming no erosion, a case that could be interpreted as corresponding to a strong effect of the biofilm (notice that equilibrium states are possible also when the biofilm is absent), we can promptly analyze stable equilibria resulting from the balance between the sediment transport terms (Figure 13). Differences between Spartina and mangroves are noticeable for large rates of sea level rise, as mangroves are not as resilient to accelerating sea level rise rates. Spartina can sustain larger RRSLR, because of the additional trapping term and for the higher production of organic soil at low elevations.

Our results confirm that the balance between physical and biological processes leads to the emergence of specific and difficult-to-predict system configurations. These configurations depend on the type of vegetation considered and the eventual presence of biostabilization factors like biofilms. The presence of different types of vegetation, either salt-marsh vegetation or mangroves in this study, can lead to different stable states for the system, even when the same external drivers are considered. The two types of vegetation considered affect the physical processes in different ways but overall there is an equifinality effect so that similar end states are achieved by different means. Salt marshes are more effective at trapping sediments through their 
foliage system. In contrast, mangroves trap less suspended sediment because most of the canopy is above the water surface at high tide.

Through different processes, both types of vegetation stimulate and reinforce accretionary patterns, which is why most of the stable states encountered for the two types of vegetation are similar. On the other hand, the time to reach a stable state is highly dependent on the type of vegetation considered and, as a result of the slower growth and adaptation, it takes a longer time for mangroves to reach a stable state. This notion suggests that current mangrove areas may be significantly lagging behind recent variations in RRSLR (or in the available suspended sediment concentration) and may be further away from equilibrium than marsh systems D'Alpaos et al. (2011).

Model results show sensitivity to the specific parameter values used in the representation of biophysical interactions. In this respect, it is necessary to reiterate that the strength of this type of "exploratory" (sensu Murray (2003)) mathematical models lies in their ability to show how simple interactions can lead to a variety of stable states qualitatively comparable to observations of natural systems. This approach, which implies focussing on a subset of interactions is limited by the inherent difficulties related to simulating multiple nonlinear feedbacks. In this respect, the case of biostabilization driven by the presence of biofilms is exemplary. As shown in our results, the inclusion of biofilm dynamics profoundly affects the overall system response. At the same time, it has to be recognized that our inclusion of biofilm in the model only deals with one physical aspect of the actual processes (how biofilm affects threshold for resuspension). However, the presence of biofilm structures also represents an appetible food source, which almost inevitably attracts macrofauna (see for example Armitage and Fong (2006); Boyer and Fong (2005)), implying biofilm grazing and active sediment disturbance. These feedbacks, induced by biophysical interactions not included in the model, could reduce the effectiveness of biofilm as a sediment stabilizer. It appears evident that more studies are needed to unravel which biophysical feedbacks should be included (see also Murray et al. (2008)), especially when multiple interactions are involved. A possible development of the present approach to biofilm dynamics could include turbidity limitations on microphytobenthos growth, which leads to a positive, as yet unexplored, feedback loop: increased resuspension increases water turbidity, thus reducing biofilm growth and promoting further erosion. As for all representations of natural phenomena, the list of model limitations can be rather long, so that it should be stressed that results should be interpreted qualitatively. Neverthe- 
less, our results strongly suggest that biofilm dynamics play an important role and that they exert a fundamental control on the long-term evolution of intertidal environments.

Overall, our results confirm the hypothesis that tidal environments, at high (marsh dominated) and low latitudes (mangrove dominated) are shaped by biophysical feedbacks and that the tipping of the system from one stable state to another depends not only on the external drivers but also on the intrinsic interactions arising from system components. The implications, relevant to researchers and practitioners, are that changes in the drivers (e.g., a change in the rate of sea level rise) or other types of disturbances can trigger a change in the system configurations possibly leading to a very different type of attractor/stable state. Such implication, however, needs to be further explored in a more realistic spatially-explicit context, as it has been suggested that the transitions experienced by spatially-extended system may be more gradual than the sudden collapses suggested by 0D models (Da Lio et al., 2013). With all their limitations our results highlight the relative role of different processes and of different vegetation types, and are especially relevant in the context of impact assessments and environmental restoration at times when external drivers are rapidly undergoing significant changes.

\section{Acknowledgements}

This work has been partially funded by the Augusto González Linares programme (University of Cantabria), by the Spanish Government research project CTM2012-35398, cofunded by FEDER funds (E.U.). We thank S. Mudd and one anonymous reviewer for their insightful and constructive comments.

\section{References}

Adam, P., 1993. Saltmarsh ecology. Cambridge University Press.

Armitage, A. R., Fong, P., 2006. Predation and physical disturbance by crabs reduce the relative impacts of nutrients in a tidal mudflat. Marine Ecology Progress Series 313, 205-213.

Berger, U., Hildenbrandt, H., 2000. A new approach to spatially explicit modelling of forest dynamics: spacing, ageing and neighbourhood competition of mangrove trees. Ecological Modelling 132 (3), 287-302. 
Boyer, K. E., Fong, P., 2005. Co-occurrence of habitat-modifying invertebrates: effects on structural and functional properties of a created salt marsh. Oecologia 143 (4), 619-628.

Carniello, L., Defina, A., Fagherazzi, S., D'alpaos, L., 2005. A combined wind wave-tidal model for the venice lagoon, italy. Journal of Geophysical Research: Earth Surface (2003-2012) 110 (F4).

CERC, 1984. Shore protection manual / [prepared for department of the army, us army corps of engineers]. v.1, 652 .

Chen, R., Twilley, R. R., 1998. A gap dynamic model of mangrove forest development along gradients of soil salinity and nutrient resources. Journal of Ecology 86 (1), 37-51.

Coco, G., Zhou, Z., van Maanen, B., Olabarrieta, M., Tinoco, R., Townend, I., 2013. Morphodynamics of tidal networks: Advances and challenges. Marine Geology 346, 1-16.

Comley, B., McGuinness, K., 2005. Above-and below-ground biomass, and allometry, of four common northern australian mangroves. Australian Journal of Botany 53 (5), 431-436.

Da Lio, C., D’Alpaos, A., Marani, M., 2013. The secret gardener: vegetation and the emergence of biogeomorphic patterns in tidal environments. Philosophical Transactions of the Royal Society A: Mathematical, Physical and Engineering Sciences 371 (2004), 20120367.

D’Alpaos, A., Lanzoni, S., Marani, M., Bonometto, A., Cecconi, G., Rinaldo, A., 2007a. Spontaneous tidal network formation within a constructed salt marsh: Observations and morphodynamic modelling. Geomorphology 91 (3-4), 186-197.

D’Alpaos, A., Lanzoni, S., Marani, M., Rinaldo, A., 2007b. Landscape evolution in tidal embayments: Modeling the interplay of erosion, sedimentation, and vegetation dynamics. J. Geophys. Res. 112, F01008, doi:10.1029/2006JF000537.

D’Alpaos, A., Lanzoni, S., Mudd, S. M., Fagherazzi, S., 2006. Modeling the influence of hydroperiod and vegetation on the cross-sectional formation of tidal channels. Estuarine, Coastal and Shelf Science 69, 311-324. 
D’Alpaos, A., Mudd, S., Carniello, L., 2011. Dynamic response of marshes to perturbations in suspended sediment concentrations and rates of relative sea level rise. Journal of Geophysical Research: Earth Surface (2003-2012) $116(\mathrm{~F} 4)$.

Darwin, C., 1881/2013. The formation of vegetable mould through the action of wormswith observations of their habits. Tredition classics.

Defina, A., Carniello, L., Fagherazzi, S., D’Alpaos, L., 2007. Self-organization of shallow basins in tidal flats and salt marshes. Journal of Geophysical Research: Earth Surface (2003-2012) 112 (F3).

Fagherazzi, S., Carniello, L., D’Alpaos, L., Defina, A., 2006. Critical bifurcation of shallow microtidal landforms in tidal flats and salt marshes. Proc. Natl. Acad. Sci. U. S. A. 103 (22), 8337-8341.

French, J. R., 1993. Numerical simulation of vertical marsh growth and adjustment to accelerated sea-level rise, north norfolk, uk. Earth Surface Processes and Landforms 18 (1), 63-81.

Friess, D. A., Krauss, K. W., Horstman, E. M., Balke, T., Bouma, T. J., Galli, D., Webb, E. L., 2012. Are all intertidal wetlands naturally created equal? bottlenecks, thresholds and knowledge gaps to mangrove and saltmarsh ecosystems. Biological Reviews 87 (2), 346-366.

Furukawa, K., Wolanski, E., Mueller, H., 1997. Currents and sediment transport in mangrove forests. Estuarine, Coastal and Shelf Science 44 (3), $301-310$.

Green, M. O., Coco, G., 2014. Review of wave-driven sediment resuspension and transport in estuaries. Reviews of Geophysics 52 (1), 77-117.

Kirwan, M. L., Murray, A. B., Apr. 2007. A coupled geomorphic and ecological model of tidal marsh evolution. Proceedings of the National Academy of Sciences 104 (15), 6118-6122.

Malarkey, J., Baas, J. H., Hope, J. A., Aspden, R. J., Parsons, D. R., Peakall, J., Paterson, D. M., Schindler, R. J., Ye, L., Lichtman, I. D., et al., 2015. The pervasive role of biological cohesion in bedform development. Nature communications 6 . 
Marani, M., Da Lio, C., DAlpaos, A., 2013. Vegetation engineers marsh morphology through multiple competing stable states. Proceedings of the National Academy of Sciences 110 (9), 3259-3263.

Marani, M., D'Alpaos, A., Lanzoni, S., Carniello, L., Rinaldo, A., 2007. Biologically-controlled multiple equilibria of tidal landforms and the fate of the venice lagoon. Geophysical Research Letters 34 (11).

Marani, M., D’Alpaos, A., Lanzoni, S., Carniello, L., Rinaldo, A., 2010. The importance of being coupled: Stable states and catastrophic shifts in tidal biomorphodynamics. Journal of Geophysical Research: Earth Surface (2003-2012) 115 (F4).

Mariotti, G., Fagherazzi, S., 2010. A numerical model for the coupled longterm evolution of salt marshes and tidal flats. J. Geophys. Res. 115, F01004.

Mariotti, G., Fagherazzi, S., 2012. Modeling the effect of tides and waves on benthic biofilms. Journal of Geophysical Research: Biogeosciences (20052012) 117 (G4).

Morris, J. T., Sundareshwar, P., Nietch, C. T., Kjerfve, B., Cahoon, D. R., 2002. Responses of coastal wetlands to rising sea level. Ecology 83 (10), 2869-2877.

Mudd, S. M., D'Alpaos, A., Morris, J. T., 2010. How does vegetation affect sedimentation on tidal marshes? investigating particle capture and hydrodynamic controls on biologically mediated sedimentation. Journal of Geophysical Research: Earth Surface (2003-2012) 115 (F3).

Mudd, S. M., Fagherazzi, S., Morris, J. T., Furbish, D. J., 2004. Flow,sedimentation, and biomass production on a vegetated salt marsh in south carolina: Toward a predictive model of marsh morphologic and ecologic evolution. The Ecogeomorphology of Salt Marshes, Coastal Estuarine Stud.

Mudd, S. M., Howell, S. M., Morris, J. T., 2009. Impact of dynamic feedbacks between sedimentation, sea-level rise, and biomass production on nearsurface marsh stratigraphy and carbon accumulation. Estuarine, Coastal and Shelf Science 82 (3), 377-389. 
Murray, A., Knaapen, M., Tal, M., Kirwan, M., 2008. Biomorphodynamics: Physical-biological feedbacks that shape landscapes. Water Resources Research 44 (11).

Murray, A. B., 2003. Contrasting the goals, strategies, and predictions associated with simplified numerical models and detailed simulations. GEOPHYSICAL MONOGRAPH-AMERICAN GEOPHYSICAL UNION 135, 151-168.

Nepf, H. M., 2012. Flow and transport in regions with aquatic vegetation. Annual Review of Fluid Mechanics 44, 123-142.

Spalding, M., Spalding, M., Kainuma, M., Collins, L., 2010. World atlas of mangroves. Earthscan.

Temmerman, S., Bouma, T. J., Van de Koppel, J., Van derWal, D., De Vries, M. B., Herman, P. M. J., 2007. Vegetation causes channel erosion in a tidal landscape. GEOLOGY 35, 631-634.

Temmerman, S., Govers, G., Meire, P., Wartel, S., 2003. Modelling longterm tidal marsh growth under changing tidal conditions and suspended sediment concentrations, scheldt estuary, belgium. Marine Geology 193 (1), 151-169.

Temmerman, S., Moonen, P., Schoelynck, J., Govers, G., Bouma, T. J., 2012. Impact of vegetation die-off on spatial flow patterns over a tidal marsh. Geophysical Research Letters 39 (3).

van Maanen, B., Coco, G., Bryan, K., 2011. The effects of mangroves on the morphological response of tidal embayments to sea level rise. In: River, Coastal and Estuarine Morphodynamics: RCEM2011, Tsinghua University Press, Beijing. pp. 657-667.

van Maanen, B., Coco, G., Bryan, K., 2015. On the ecogeomorphological feedbacks that control tidal channel network evolution in a sandy mangrove setting. In: Proc. R. Soc. A. Vol. 471. The Royal Society, p. 20150115.

Vandenbruwaene, W., Meire, P., Temmerman, S., 2012. Formation and evolution of a tidal channel network within a constructed tidal marsh. Geomorphology 151, 114-125. 
Venier, C., D'Alpaos, A., Marani, M., 2014. Evaluation of sediment properties using wind and turbidity observations in the shallow tidal areas of the venice lagoon. Journal of Geophysical Research: Earth Surface 119 (7), 1604-1616. 


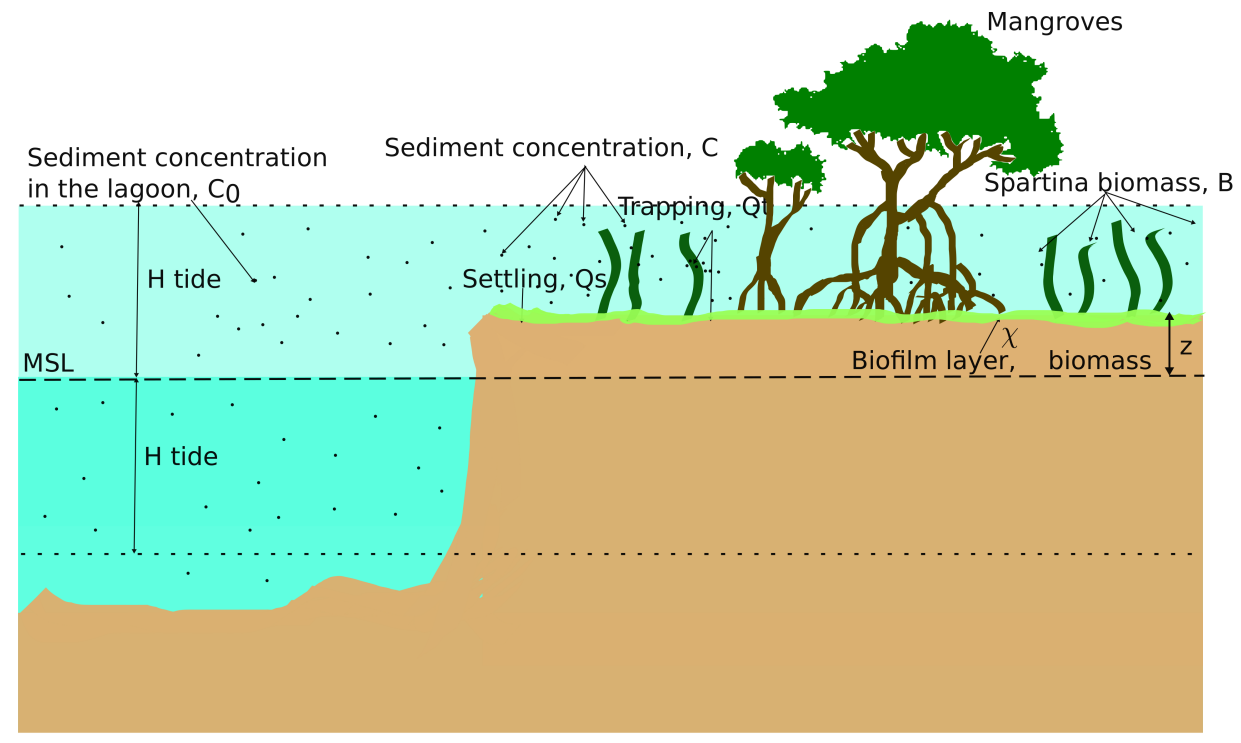

Figure 1: Elevation model sketch. Settling, trapping and organic matter production increase the platform elevation while erosion has the opposite effect. 

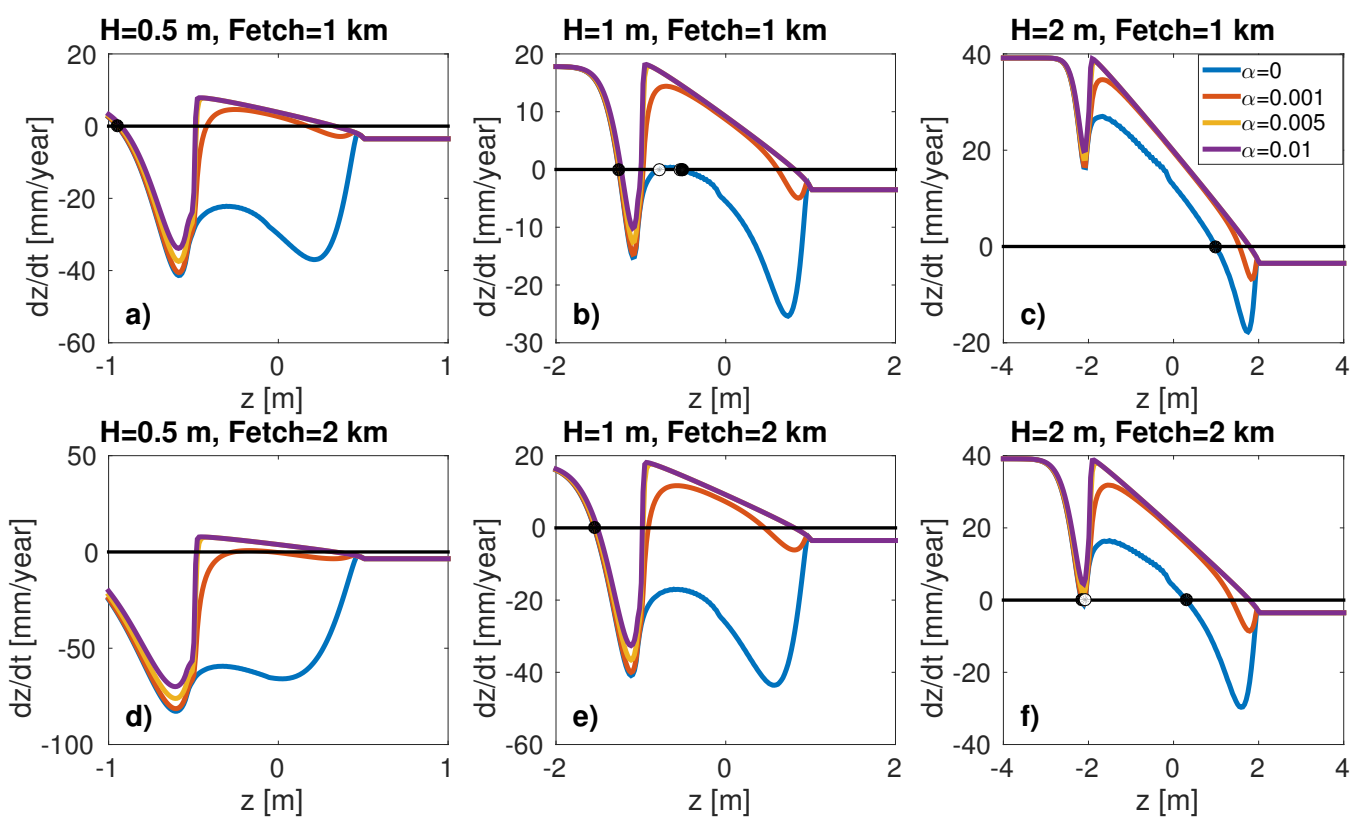

Figure 2: Stability curves for the Spartina-dominated case for different fetch distances, tidal amplitudes, and values of the proportionality factor quantifying the effect of biomass density ( $\alpha=0$ implies no biofilm). (a) fetch $=1 \mathrm{~km}, \mathrm{H}=0.5 \mathrm{~m}$; (b) fetch=1 km, H=1.0 $\mathrm{m} ;$ (c) fetch=1 km, H=1.5 m; (d) fetch $=2 \mathrm{~km}, \mathrm{H}=0.5 \mathrm{~m} ;$ (e) fetch=2 km, H=1.0 m; (f) fetch $=2 \mathrm{~km}, \mathrm{H}=1.5 \mathrm{~m}$. Closed and open circles indicate stable and unstable states, respectively (only plotted for the no-biofilm case). $\mathrm{R}=3.5 \mathrm{~mm} / \mathrm{y}$ and $\tau_{c 0}=0.2 \mathrm{~Pa}$ are assumed. Notice that the vertical and horizontal scales differ between panels. 

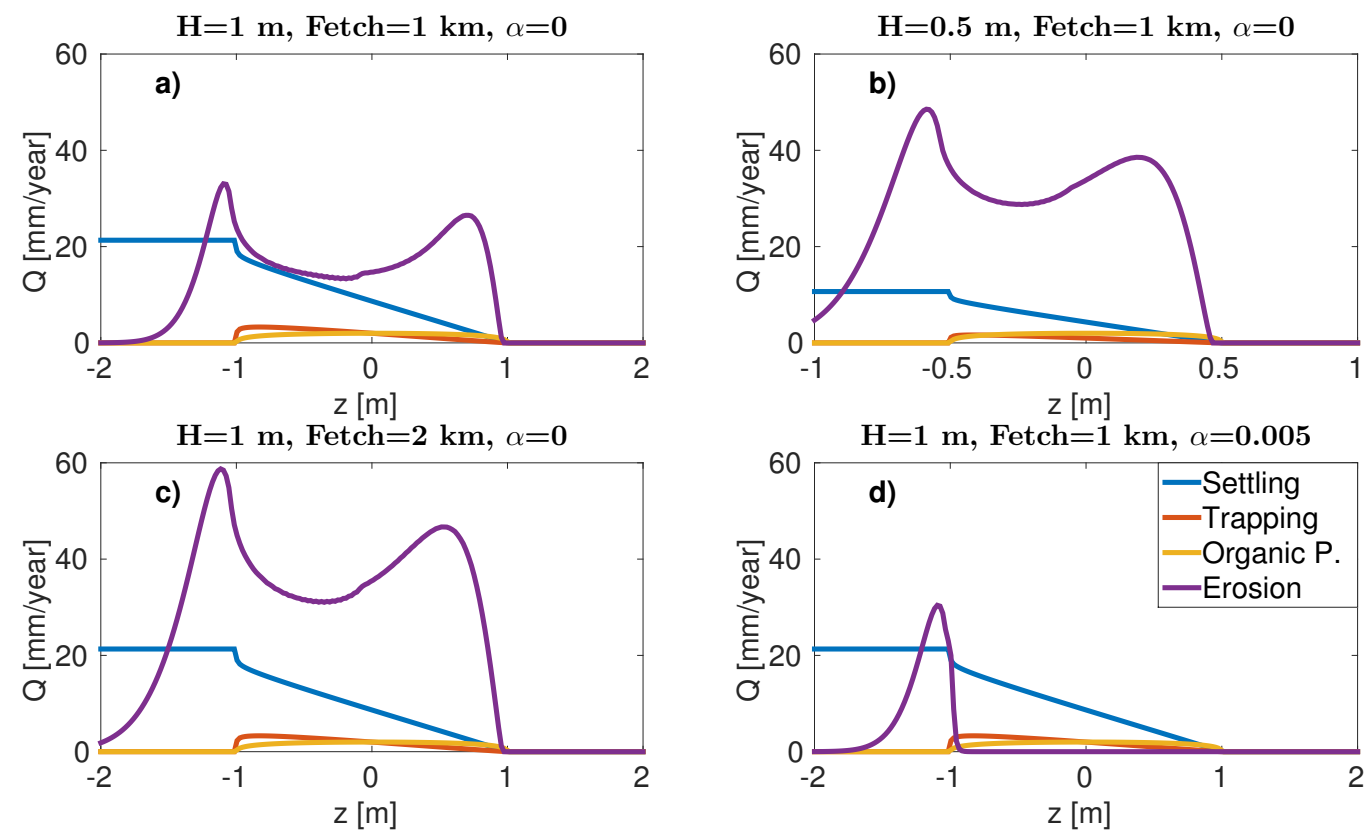

Figure 3: Contribution of the different sediment transport terms (see legend) to the total accretion rate for the Spartina case. (a) fetch $=1 \mathrm{~km}, \mathrm{H}=1.0 \mathrm{~m}, \alpha=0$; (b) fetch=1 km, $\mathrm{H}=0.5 \mathrm{~m}, \alpha=0$; (c) fetch=2 km, $\mathrm{H}=1.0 \mathrm{~m}, \alpha=0$; (d) fetch $=1 \mathrm{~km}, \mathrm{H}=1.0 \mathrm{~m}, \alpha=0.005$. Unless otherwise indicated, parameters are the same as in the caption of Figure 2). 

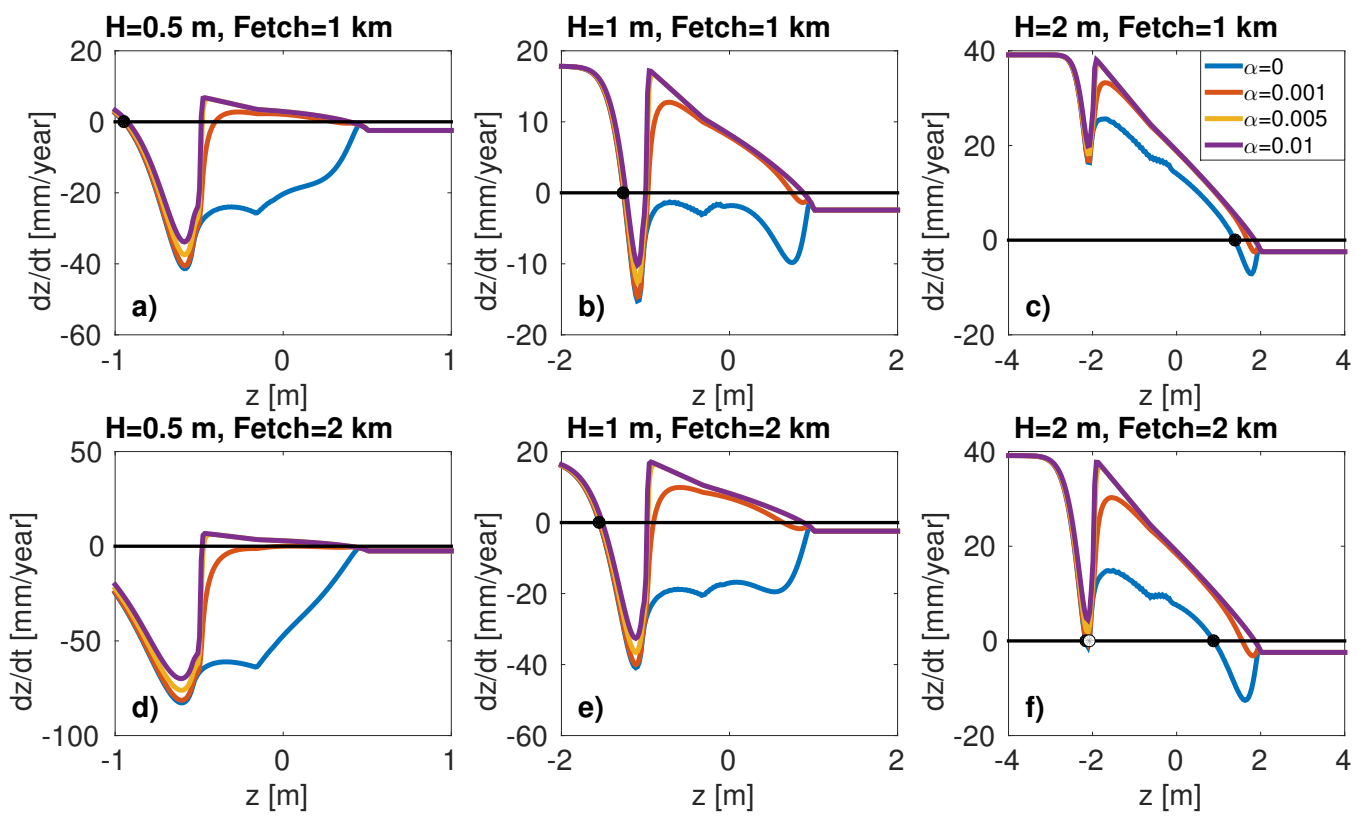

Figure 4: Stability curves for the mangrove case for different fetch lengths, tidal amplitudes, and values of the proportionality factor quantifying the effect of biomass density ( $\alpha=0$ implies no biofilm). (a) fetch $=1 \mathrm{~km}, \mathrm{H}=0.5 \mathrm{~m} ;$ (b) fetch=1 km, H=1.0 m; (c) fetch=1 km, H=1.5 m; (d) fetch $=2 \mathrm{~km}, \mathrm{H}=0.5 \mathrm{~m}$; (e) fetch=2 km, H=1.0 m; (f) fetch=2 $\mathrm{km}, \mathrm{H}=1.5 \mathrm{~m}$. Black and white dots indicate stable and unstable states, respectively (only plotted for the curve with no biofilm). $\mathrm{R}=3.5 \mathrm{~mm} / \mathrm{y}$ and $\tau_{c 0}=0.2 \mathrm{~Pa}$ are assumed. Notice that the vertical and horizontal scales differ between panels. 

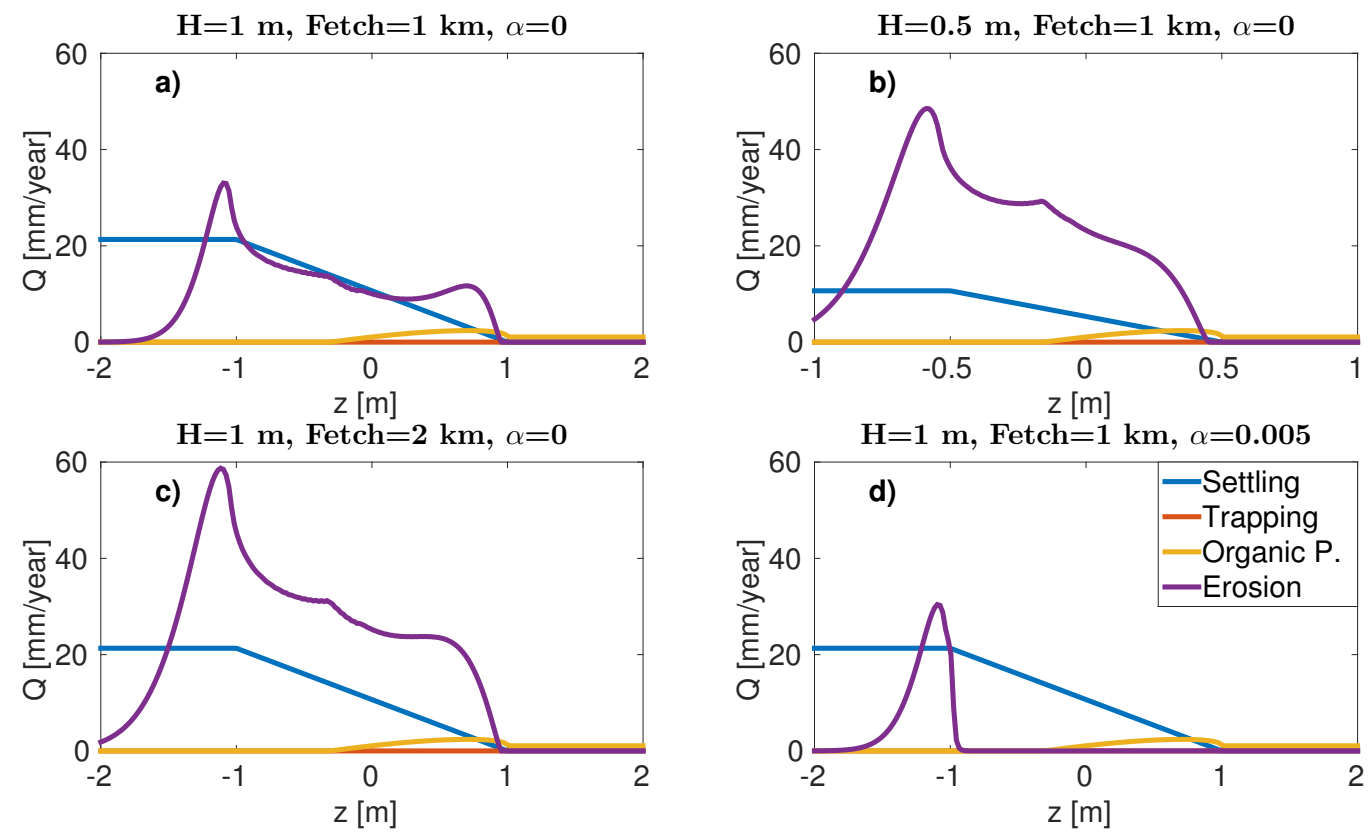

Figure 5: Contribution of the different sediment transport terms (see legend) to the accretion rate for the Mangrove-dominated case. (a) fetch $=1 \mathrm{~km}, \mathrm{H}=1.0 \mathrm{~m}, \alpha=0$; (b) fetch=1 km, H=0.5 m, $\alpha=0$; (c) fetch=2 km, H=1.0 m, $\alpha=0 ;(d)$ fetch = $1 \mathrm{~km}, \mathrm{H}=1.0$ $\mathrm{m}, \alpha=0.005$. Unless otherwise indicated, parameters are the same as in the caption of Figure 4). 

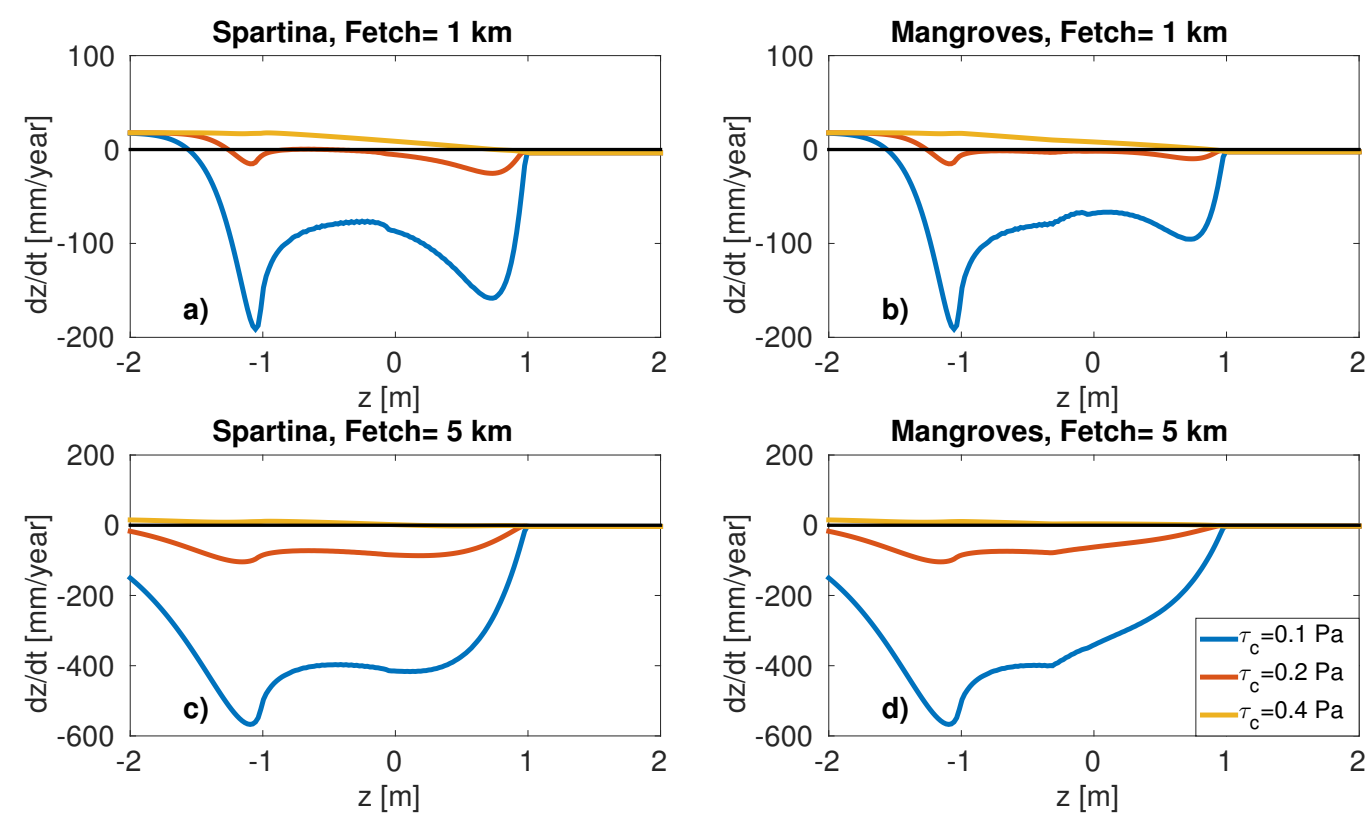

Figure 6: Stability curves for (a) Spartina-dominated, fetch $=1 \mathrm{~km}$; (b) Mangrovedominated, fetch $=1 \mathrm{~km}$; Spartina-dominated, fetch $=5 \mathrm{~km} ;$ (d) Mangrove-dominated, fetch $=5 \mathrm{~km}$. Tidal amplitude is $1 \mathrm{~m}$ and different values of $\tau_{c}$ are considered (see legend). $\mathrm{R}=3.5 \mathrm{~mm} / \mathrm{y}$ and $\alpha=0$ are assumed. Notice that the vertical scale differs between panels. 

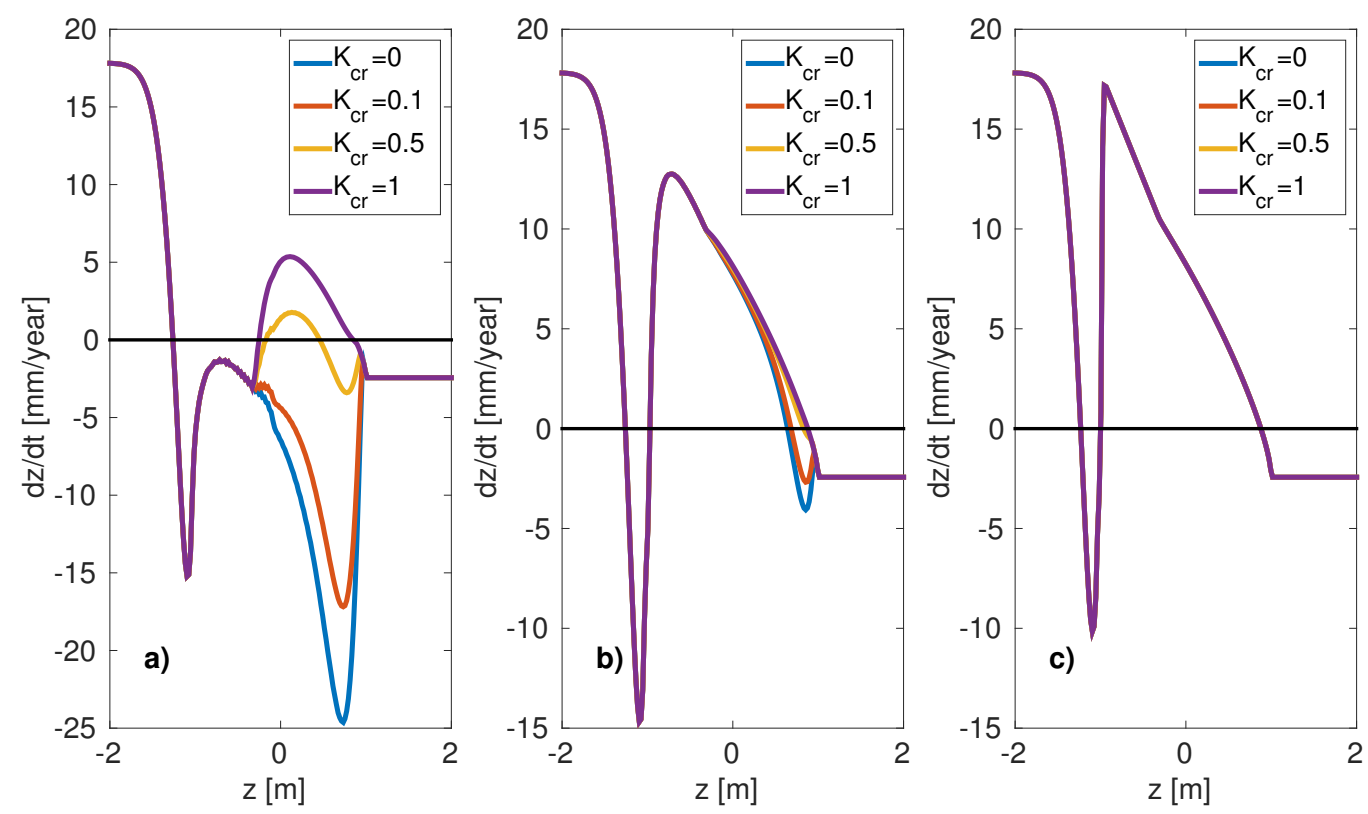

Figure 7: Stability curves for the mangrove case with different values of the parameter $K_{c r}$ (see legend) and (a) $\alpha=0$, (b) $\alpha=0.001$, (c) $\alpha=0.01$ ). Fetch distance is $1 \mathrm{~km}$, tidal range is $1 \mathrm{~m}$ ). Notice that the vertical scale differs between panels. 

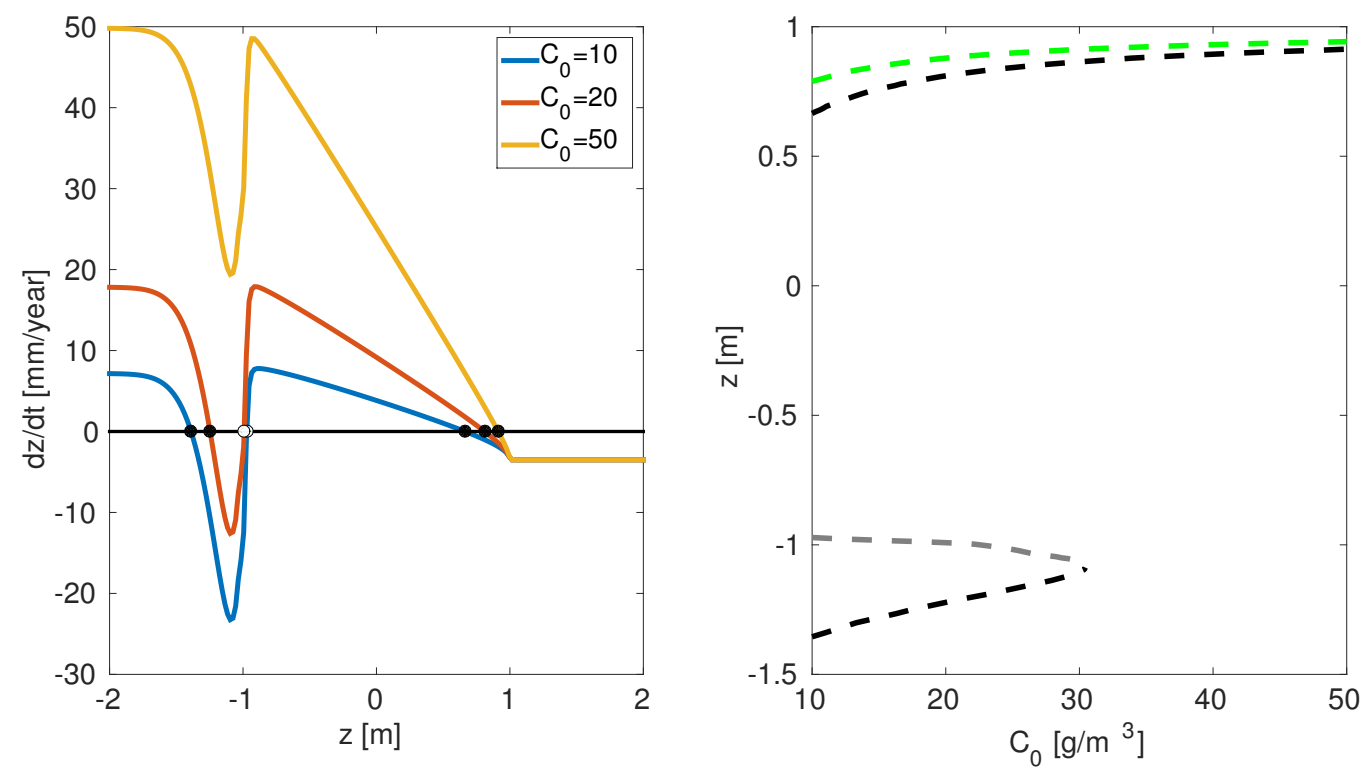

Figure 8: Example of stability curves (left panel) for the Spartina case and different values of the suspended sediment concentration (see legend). The right panel shows the elevation of the stable states for Spartina (black lines) and mangroves (green line). The unstable equilibrium points are represented by the grey line. For $z<-0.5 \mathrm{~m}$ the grey and black lines are the same for Spartina and mangroves because at such depths vegetation has no effect. In these simulations the fetch distance is $1 \mathrm{~km}$, tidal range is $1 \mathrm{~m}, \alpha=0.005$, $\tau_{c r 0}=0.2 \mathrm{~Pa}$ and $R=3.5 \mathrm{~mm} / \mathrm{y}$. 

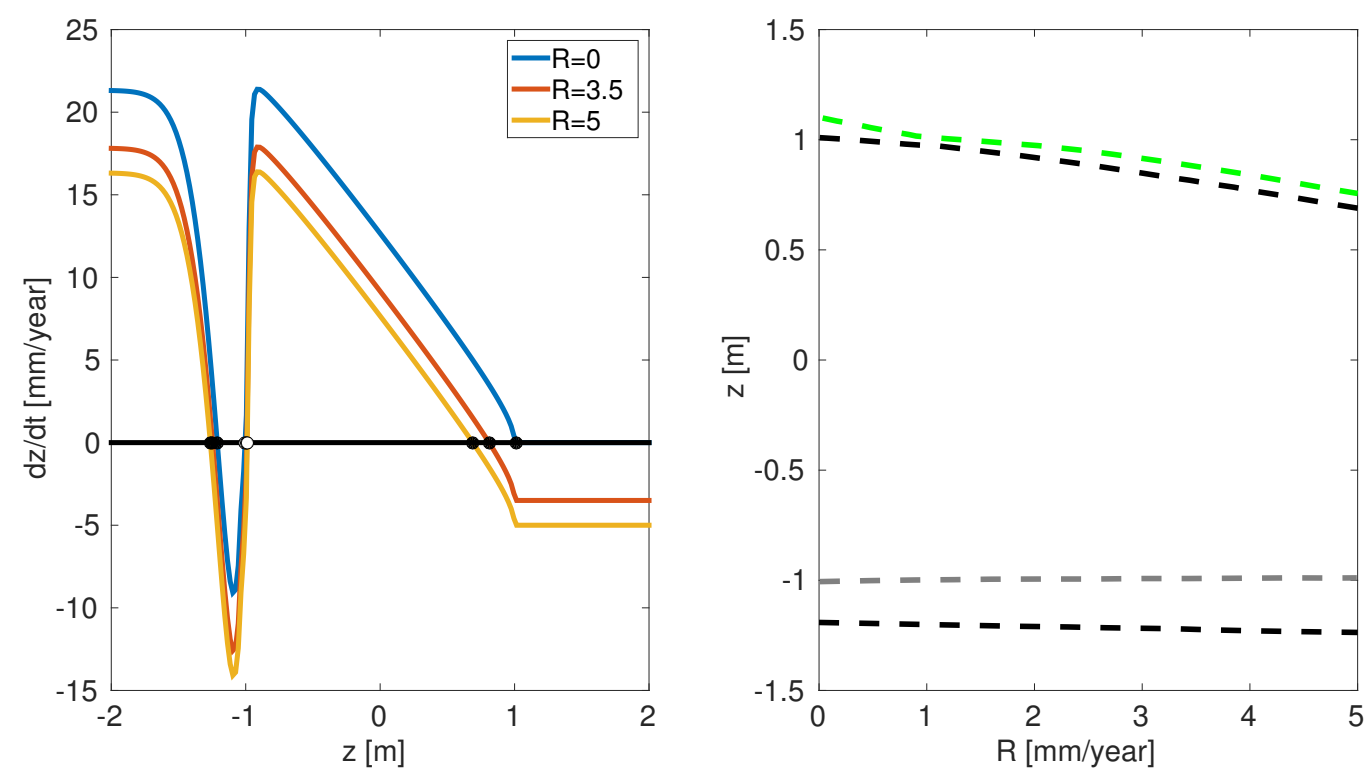

Figure 9: Stability curves (left panel) for the Spartina-dominated case for different values of the relative sea level rise. The right panel shows the elevation of the stable points for Spartina (black lines) and mangroves (green line). The unstable equilibrium points are represented by the grey line. For $z<-0.5 \mathrm{~m}$ the grey and black lines are the same for Spartina and mangroves because at such depths vegetation has no effect. In these simulations the fetch distance is $1 \mathrm{~km}$, tidal range is $1 \mathrm{~m}, \alpha=0.005, \tau_{c r 0}=0.2 \mathrm{~Pa}$ and $C_{0}=20 \mathrm{~g} / \mathrm{m}^{3}$. 


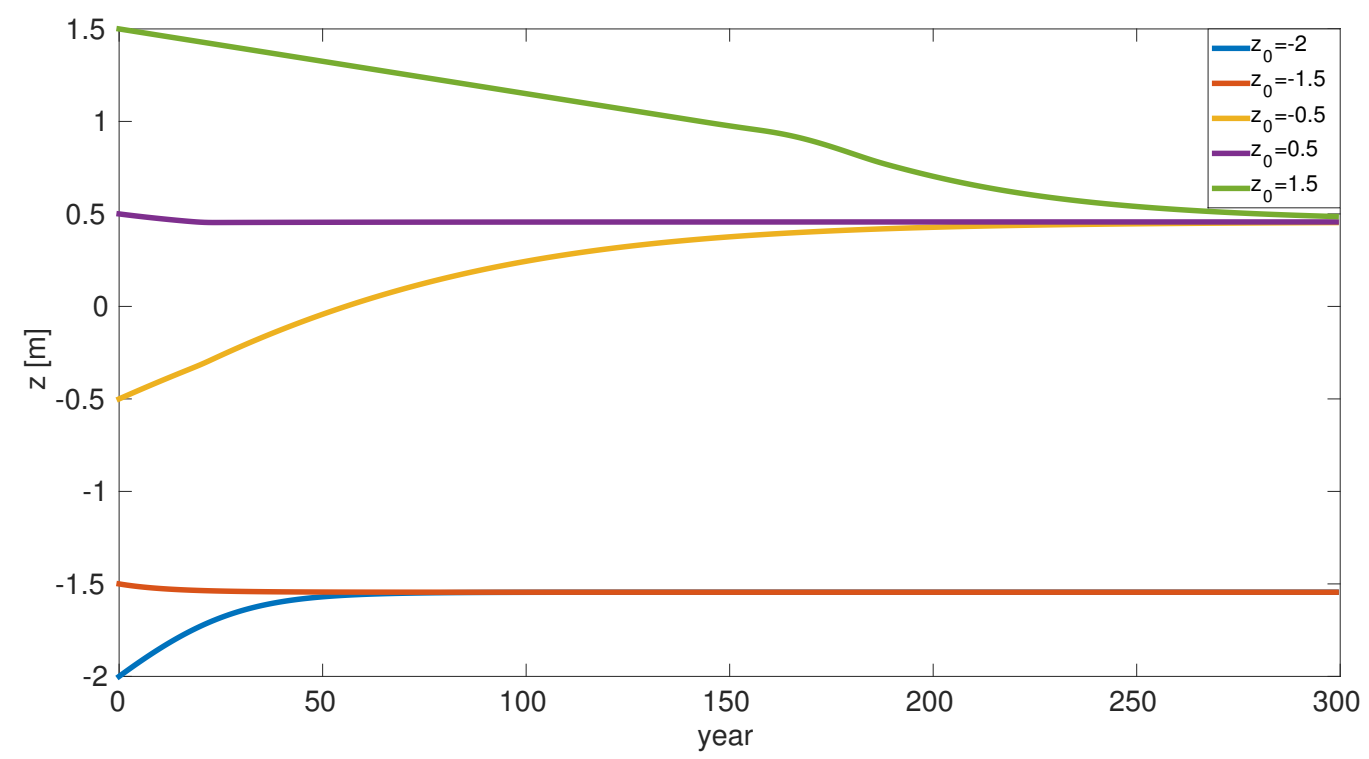

Figure 10: Temporal evolution and dependence on initial bed elevation to reach a stable state for the Spartina case. the fetch distance is $2 \mathrm{~km}$, tidal range is $1 \mathrm{~m}, \alpha=0.001$, $\tau_{c r 0}=0.2 \mathrm{~Pa}, C_{0}=20 \mathrm{~g} / \mathrm{m}^{3}$ and $R=3.5 \mathrm{~mm} / \mathrm{y}$

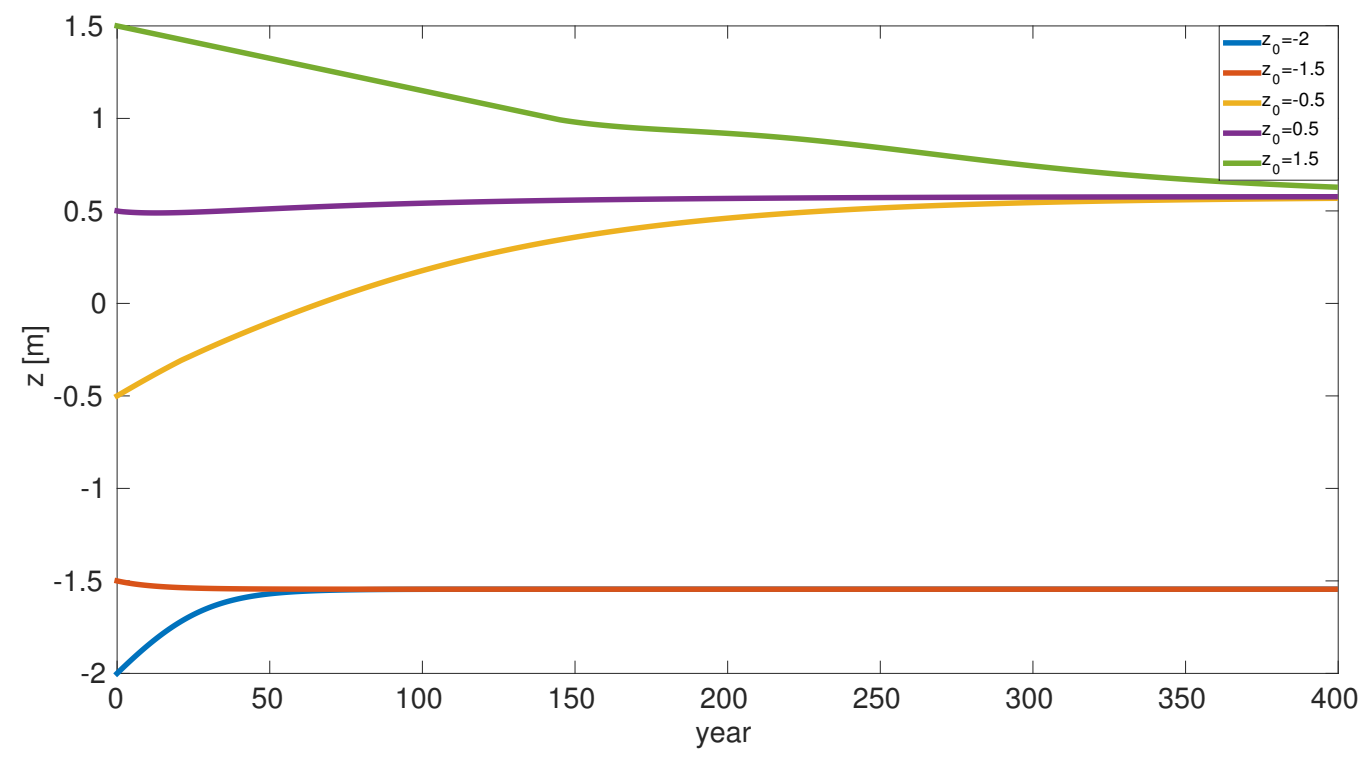

Figure 11: Temporal evolution and dependence on initial bed elevation to reach a stable state for the mangrove case. The fetch distance is $2 \mathrm{~km}$, tidal range is $1 \mathrm{~m}, \alpha=0.001$, $K_{c r}=0.25, \tau_{c r 0}=0.2 \mathrm{~Pa}, C_{0}=20 \mathrm{~g} / \mathrm{m}^{3}$ and $R=3.5 \mathrm{~mm} / \mathrm{y}$ 

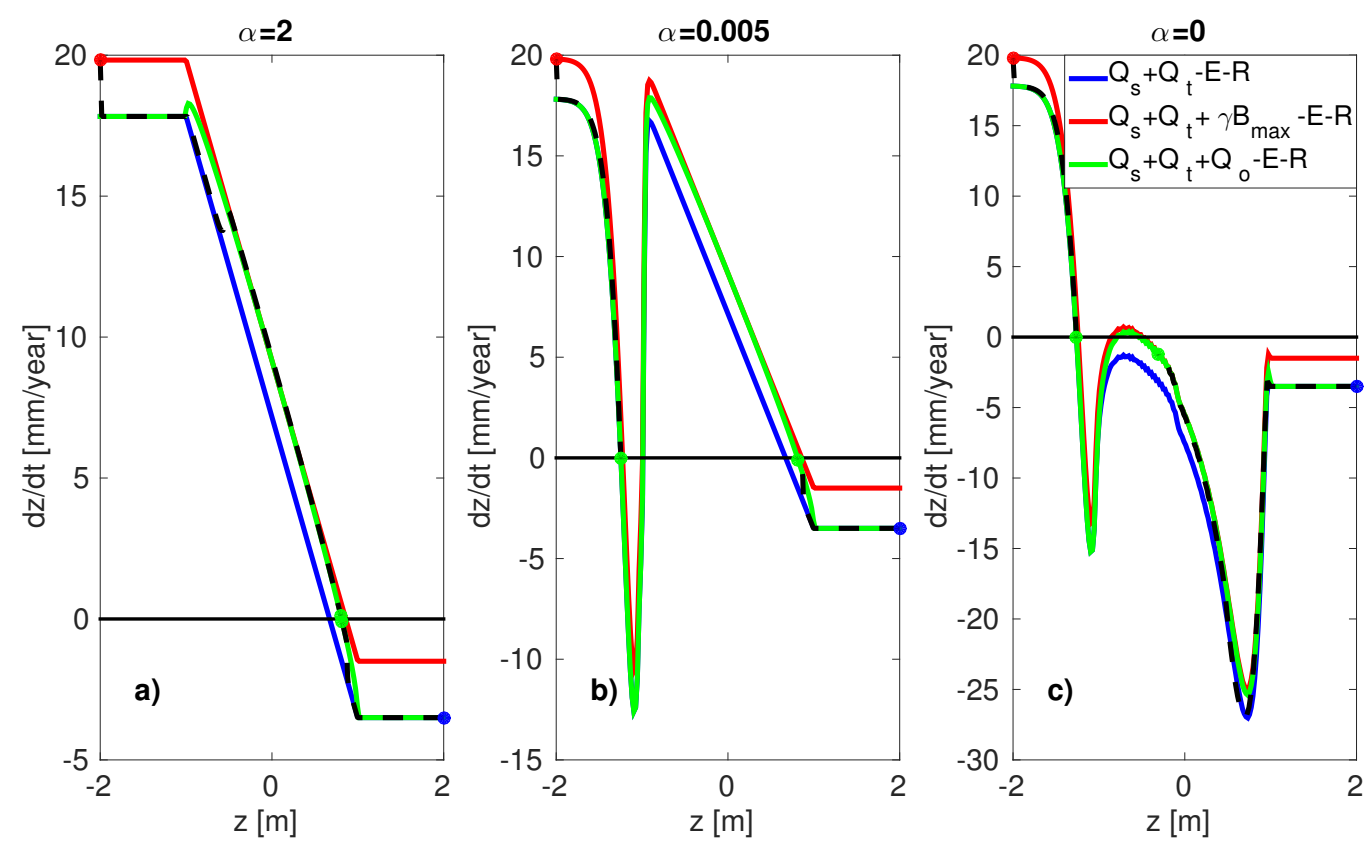

Figure 12: Stability curves for the Spartina case. The fetch distance is $1 \mathrm{~km}$, tidal range is $1 \mathrm{~m}, \gamma=0.002 \mathrm{~mm} / \mathrm{y} /\left(\mathrm{g} / \mathrm{m}^{2}\right), \tau_{c r 0}=0.2 \mathrm{~Pa}, C_{0}=20 \mathrm{~g} / \mathrm{m}^{3}$ and $R=3.5 \mathrm{~mm} / \mathrm{y}$. (a) $\alpha=2$, (b) $\alpha=0.005$, (c) $\alpha=0$. The dashed black line shows the trajectory of the system when the initial conditions are either the red or the blue dot (low and high tide, respectively). The green dots represent stable states. Notice that the vertical scale differs between panels. 

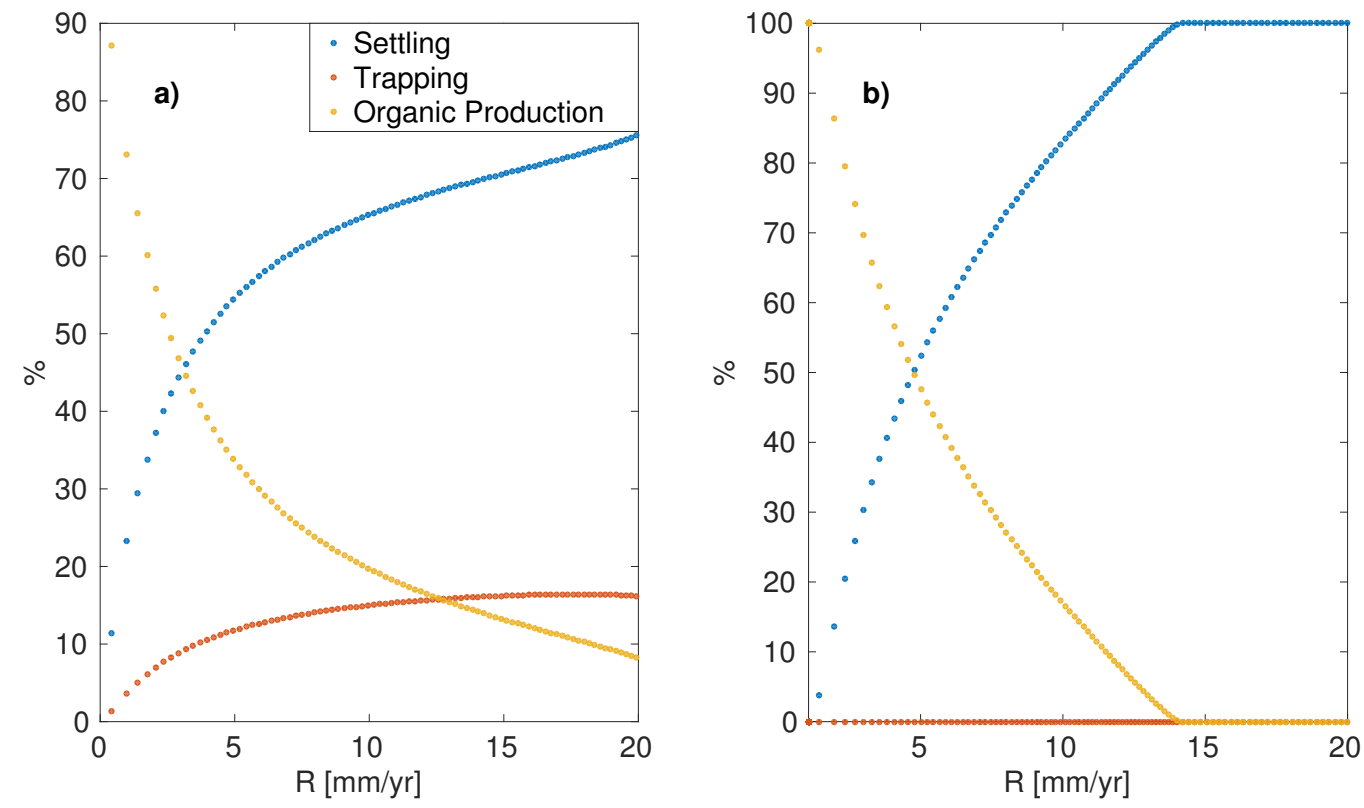

Figure 13: Stable states and sediment balance for the (a) Spartina and (b) mangrove cases. The fetch distance is $1 \mathrm{~km}$, tidal amplitude is $2 \mathrm{~m}, \gamma=0.002 \mathrm{~mm} / \mathrm{y} /\left(\mathrm{g} / \mathrm{m}^{2}\right), C_{0}=20 \mathrm{~g} / \mathrm{m}^{3}$. 